\title{
Emergency science: Epistemological insights on the response to COVID-19 pandemics
}

\author{
Carlos Magno Castelo Branco Fortaleza MD, $\mathrm{PhD}^{1}$ (1) \\ Department of Infectious Diseases, Botucatu School of Medicine, São Paulo State University (UNESP). City of Botucatu, São Paulo Sate, Brazil
}

To the Editor-In the year 2000, South Africa President Thado Mbeki was the spokesman of an organized movement of AIDS denialism, which still echoes in many countries, such as Russia. ${ }^{1}$ When facing pandemics, scientific denialism may adopt several faces and disguises. The "common cold" argument against the potential severity of COVID-19 spread through social media. The balance of socioeconomic versus sanitary achievements of lockdown may be contaminated by global ideological discussions and/or local political interests. ${ }^{2}$ Public health challenges become more intense when decisions depend on mathematical modeling and scarce, suboptimal empirical evidence. Such occurrences obviously have implications for infection control and patient safety.

When an ongoing pandemics require rapid translation of research findings into practice guidelines, the epistemological basis of modern public health must be discussed. Here, I submit the scientific basis of the response to the pandemic to critical scrutiny based on ideas from renowned philosophers of science. Additionally, I discuss the policy of disseminating knowledge in times of global emergency.

"Unlike (...) doctors, the scientist need not choose problems because they urgently need solution," stated Thomas Kuhn (19221996) is his masterpiece The Structure of Scientific Revolutions. ${ }^{3}$ Kuhn was too young to have experienced 1918 influenza pandemics, but he did live the first decade of AIDS emergence. His statement that sciences develop inside or around a historically determined paradigm was highly praised by sociologists and anthropologists, and he influenced (nonorthodoxically, I must clarify) eminent epidemiologists. ${ }^{4}$ Different paradigms are incommensurable, an adjective by which Kuhn means that when scientist sees the world from different perspectives, their contradictions just cannot be solved by discussion or experiment. Well, we must ask if the germ theory is one of those Kuhnian paradigms. From Kuhn's perspective, all the science raised in the pandemic response has a historical, but not epistemological, justification.

Karl Popper (1902-1994) dedicated all his life to explore what he called "the two fundamental problems in the theory of knowledge." First is the problem of induction, as described by David Hume (1711-1776), which states that no matter how many

Author for correspondence: Carlos Magno Castelo Branco Fortaleza, Avenue Mario Rubens Guimarães Montenegro, S/N - Botucatu School of Medicine City of Botucatu, São Paulo State, Brazil, CEP/ZIP 18618687, E-mail: carlos.fortaleza@unesp.br

PREVIOUS PRESENTATION: A preliminary version of this manuscript appeared in a preprint repository (https://preprints.scielo.org/index.php/scielo/preprint/view/162).

Cite this article: Fortaleza CMCB. (2021). Emergency science: Epistemological insights on the response to COVID-19 pandemics. Infection Control \& Hospital Epidemiology, 42: 120-121, https://doi.org/10.1017/ice.2020.209 observations (which we can translate to scientific evidence) of "A" followed by "B," a causal association would always be a psychological rather than a logical conclusion. Second is the problem of demarcation, which is the need for a clear rule or boundary between what is scientific and what is not. ${ }^{5}$ Agreeing with Hume, Popper refused induction (the cornerstone of "evidencebased medice") and proposed that scientists should be creative in imagining theories, then rigorous in testing them both rationally and empirically. Any theory will survive as the fittest while it resists empirically based refutations. Coherently, science is defined for its possibility of empiric falsification. How does this apply to scientists fighting COVID-19? From a Popperian perspective, public response would be strengthened by a network of mutually critical researchers. Although theoretical discussion and criticism cannot be paralyzing or move too slowly while we count the dead, the scientific community may be prepared to endorse changes in public policies whenever a theory is refuted and studies point to novel, more adequate strategies.

Of greater concern is Paul Feyrabend's (1924-1994) "anything goes" statement in his famous book Against Method, ${ }^{6}$ or his criticism on modern medicine achievements in his later works. In a similar direction, New York University Philosopher Peter Unger's (born 1942) skeptical argument that "nothing can ever be really known" is, in the best hypothesis, useless, and in the worst scenario, highly dangerous if spread over all public opinion. ${ }^{7}$

Finally, an interesting way out of the epistemological puzzle is provided by Imre Lakatos's (1922-1974) insights on "Programs of Scientific Investigation." ${ }^{8}$ Lakatos attempted to reconcile Popper's and Kuhn's ideas, and he had a productive dialogue with Feyerabend. Briefly, Lakatos imagined networks of mutual criticism (like Popper) in permanent rivalry. Occasionally, one of those programs gains advantage (becomes "progressive") over others (which become "regressive"). He admits (like Kuhn) some historicity in the balance between them. Still, he fiercely advocates for a demarcation criterion for science. We must therefore assume that virological-epidemiological programs are progressive and should not only be heard by government officials but also must be given more expression in scientific journals.

This brings us to the final discussion. Peer-review has provided the basis for continuous Popperian-Lakatosian criticism, and at least in theory it provides a scientific quality badge to information. Both peer review and editing processes take time, which we do not have in the current pandemics. Hundred of studies are either published in preprint repositories or submitted to fast-track peer review. ${ }^{9}$ This obviously means loosening the critical parameters, a choice of speed over rigor. That trend is totally in accordance with Lakato's predicted privileges for progressive programs. However, it requires a permanent critical attitude from the readers and a constant state of alert in the scientific community. 
In conclusion, the response to COVID-19 does not require consensus. Criticism is perhaps the most precious principle of scientific thinking and practice. By submitting the role of science in responding to COVID-19 to the scrutiny of leading critics of mainstream science, we not only vaccinate our community against nihilistic arguments but also reinforce the human value of research activity. Research and scientific criticism must be exercised aiming to collaborate with public policies and avoiding messages of uncertainty and insecurity to the already sufficiently frightened population. Furthermore, even if we argue that there is no such thing as value-neutral science, ${ }^{10}$ we need to move our research away from political and corporate interests. Thus, in an era of extremism, science can rise as the pillar of democracy and as a movement to protect life.

Acknowledgments. A preliminary version of this manuscript appeared in a preprint repository (https://preprints.scielo.org/index.php/scielo/preprint/ view/162).

Financial support. No financial support was provided relevant to this article.

\section{References}

1. Kalichman SC. Pence, Putin, Mbeki and their HIV/AIDS-related crimes against humanity: call for social justice and behavioral science advocacy. AIDS Behav 2017;21:963-967.

2. Editorial. COVID-19: learning from experience. Lancet 2020;395:1011.

3. Kuhn TS. The Structure of Scientific Revolutions. Chicago: University of Chicago Press; 1962.

4. Susser M, Susser E. Choosing a future for epidemiology: I. Eras and paradigms. Am J Public Health 1996;86:668-673.

5. Popper K. The Two Fundamental Problems in the Theory of Knowledge. London: Routledge; 2009.

6. Feyerabend P. Against Method. London: New Left Books; 1975.

7. Unger P. Ignorance: A Case for Scepticism. Oxford: Oxford University Press; 1975.

8. Lakatos I. The Methodology of Scientific Research Programmes: Volume 1: Philosophical Papers. Cambridge: Cambridge University Press; 1980.

9. Flier JS. Covid-19 is reshaping the world of bioscience publishing. Statnews website. https://www.statnews.com/2020/03/23/bioscience-publishing-reshapedcovid-19/, 2020. Published March 23, 2020. Accessed May 5, 2020.

10. Lekka-Kowalik A. Why science cannot be value-free: understanding the rationality and responsibility of science. Sci Eng Ethics 2010;16: $33-41$.

\title{
Protecting frontline healthcare workers should be the top priority in low-resource health systems: Bangladesh and COVID-19
}

\author{
Md. Zakiul Hassan MBBS ${ }^{1, a}$ (1) , Mohammad R. Monjur ${ }^{2, a}{ }^{(1)}$, Ashley Rene Styczynski MD, PhD $^{3}$ (1), \\ Mahmudur Rahman $\mathrm{PhD}^{1}$ and Sayera Banu $\mathrm{PhD}^{1}$ \\ ${ }^{1}$ Programme for Emerging Infections, Infectious Diseases Division, icddr,b, Dhaka, Bangladesh, ${ }^{2}$ University of Newcastle, New South Wales, Australia and \\ ${ }^{3}$ Division of Infectious Diseases and Geographic Medicine, School of Medicine, Stanford University, Palo Alto, California, United States of America
}

To the Editor-In April, the World Health Organization emphasized that the global shortage of personal protective equipment (PPE) is one of the most urgent threats sabotaging our ability to control the coronavirus 2019 (COVID-19) pandemic. As high-resource health systems around the world struggle to supply adequate PPE to their frontline healthcare workers (HCWs), ${ }^{1}$ it is likely that HCWs in low- and middle-income countries (LMICs) will bear the brunt of this global supply chain shortage. In Italy, $10 \%$ of the total confirmed COVID-19 cases have been among HCWs, and 105 HCWs have died. ${ }^{2}$ In the United States, state health departments similarly revealed a high proportion of cases among HCWs: Ohio (20\%), Oklahoma (10.6\%) and Pennsylvania (4.4\%). ${ }^{3}$ Bangladesh reported its first HCW death on April 15, with 100 doctors and 57 nurses infected, and these numbers are likely to increase significantly as the country ramps

Author for correspondence: Dr Md. Zakiul Hassan, E-mail: zhassan@icddrb.org ${ }^{a}$ Authors of equal contribution.

Cite this article: Hassan MZ, et al. (2021). Protecting frontline healthcare workers should be the top priority in low-resource health systems: Bangladesh and COVID-19. Infection Control \& Hospital Epidemiology, 42: 121-122, https://doi.org/10.1017/ ice. 2020.208 up its testing efforts. ${ }^{4}$ Given the existing shortage of HCWs in Bangladesh, infection and subsequent absenteeism of HCWs from an already stretched workforce could leave Bangladesh grossly unprepared for the impending peak of the crisis.

Frontline HCWs in Bangladesh and other LMICs are particularly vulnerable to SARS-CoV-2 transmission because they work in overcrowded environments and have poor infection prevention and control (IPC) mechanisms-2 major risk factors for nosocomial infection transmission. In Bangladesh's capital, Dhaka (one of the most densely populated cities in the world), a single-center study demonstrated a median of 4 people per $10 \mathrm{~m}^{2}$ of floor space. ${ }^{5}$ The close proximity between patients, caregivers, and HCWs can serve as a dangerous vehicle for rapid viral spread, placing HCWs in Bangladesh at an especially high risk of SARS-CoV-2 transmission. Further exacerbating the situation is poor infection prevention and control (IPC) practices at baseline; $<2 \%$ of HCWs were compliant with recommended hand hygiene practices in a national survey, a result of both inadequate infrastructure and lack of IPC training. ${ }^{6}$ Many healthcare facilities in LMICs face a similar scenario; one study reported that $50 \%$ of healthcare facilities in LMICs lack piped water and $39 \%$ lack handwashing soap. ${ }^{7}$ Frontline HCWs should be equipped with the resources needed to create a safe environment for themselves and their patients, which includes access to hygiene measures and PPE in addition to adequate training on the application

(C) 2020 by The Society for Healthcare Epidemiology of America. All rights reserved. This is an Open Access article, distributed under the terms of the Creative Commons Attribution licence (http://creativecommons.org/licenses/by/4.0/), which permits unrestricted re-use, distribution, and reproduction in any medium, provided the original work is properly cited. 